\title{
LA FLEXIBILIDAD DEL PRINCIPIO DE LEGALIDAD Y LOS CRÍMENES QUE AGRAVIAN A LA HUMANIDAD
}

\author{
FERNANDO VeLÁSQUEZ V*
}

En la época contemporánea se ha producido la flexibilización del tradicional principio de legalidad, que implica una restricción a las garantías del justiciable en pro de la lucha contra la criminalidad que agravia a la humanidad, lo que se explica porque con frecuencia se trata de una manifestación delincuencial auspiciada -o sistemáticamente cometida- por los Estados totalitarios, que por supuesto no estarían interesados en legislar tipificando sus propios actos. Por ello, en tratándose de crímenes internacionales la legalidad supone la integración de los tratados internacionales a los sistemas jurídicos domésticos con plenos efectos como ley previa para hacer viable su sanción, así los mismos no estuvieran formalmente tipificados en la legislación nacional al momento de su comisión.

\section{PROVIDENCIA** \\ “CORTE SUPREMA DE JUSTICIA SALA DE CASACIÓN PENAL}

Magistrado Ponente: Dr. JOSÉ LEONIDAS BUSTOS MARTÍNEZ

Proceso $N^{\circ} 33039$

Bogotá D.C., diciembre dieciséis de dos mil diez

\section{VISTOS}

La Corte decide el recurso de apelación que interpusieron tanto la Fiscal Once de la Unidad Nacional de Justicia y Paz, como la representante judicial

\footnotetext{
* Este trabajo forma parte de las exploraciones académicas realizadas dentro de la línea de investigación en Dogmática Penal, del Grupo de Investigación en Ciencias Penales y Criminológicas "Emiro Sandoval Huertas", al cual está adscrito como investigador el autor. * Como se insertan apartes de la providencia, los pié de página tienen una numeración distinta a la original.
} 
de las víctimas de la "masacre del Salao", contra la decisión adoptada por un Magistrado con funciones de Control de Garantías de la Sala de Justicia y Paz del Tribunal Superior de Barranquilla, por medio de la cual impuso medida de aseguramiento al señor ÚBER ENRIQUE BANQUEZ MARTÍNEZ (alias "Juancho Dique") perteneciente al bloque "Héroes de los Montes de María" de las Autodefensas Unidas de Colombia, quien se encuentra recluido en la Cárcel Modelo de Barranquilla, con ocasión de los delitos imputados parcialmente.

\section{CONSIDERACIONES}

La Corte es competente para conocer de esta apelación en virtud de lo dispuesto en el artículo 26 de la Ley 975 de 2005.

Son dos los problemas jurídicos que se plantean con la apelación que ahora se resuelve: el primero se refiere al alcance del poder del juez o el magistrado con funciones de control de garantías en punto de la imposición de la medida de aseguramiento, frente a la tipificación realizada por el fiscal en la formulación de imputación; y el segundo, está relacionado con la vigencia de las leyes en el tiempo, específicamente si existe la posibilidad de que las normas del Título II del Libro Segundo del Código Penal, llamado "Delitos contra personas y bienes protegidos por el Derecho Internacional Humanitario", cuya vigencia inició el 25 de julio de 2001, se apliquen para sancionar conductas realizadas con anterioridad a esa fecha (...).

El segundo problema: 1. La Sala comienza por reivindicar el principio de legalidad reconocido en nuestra Constitución Política como bastión de protección contra la arbitrariedad, cuyo reconocimiento se origina en los reclamos de la burguesía de la Europa del Siglo XVIII que veía con enorme preocupación que no existiera precisión sobre el contenido de lo prohibido, el juez llamado a juzgar los delitos, el procedimiento a seguir, así como el monto y la clase de pena aplicable, imponiéndose, por tanto la arbitrariedad del soberano; siendo pioneros de su materialización: Montesquieu ${ }^{1}$ llamando la atención de lo peligrosa que resultaba la costumbre como fuente de derecho y la necesidad de una ley en cuyo espíritu pudiera asentarse la expresión de las leyes naturales; Hobbes ${ }^{2}$ urgiendo sobre la necesidad de leyes que limitaran el egoísmo de los hombres; Beccaría ${ }^{3}$, quien influenciado por Jean Mabillon y por Montesquieu, reclamó por la ausencia de precisión de lo que estaba prohibido y permitido, entre otras consignas de su querella humanista; Rousseau ${ }^{4}$ que abogó por la producción de la ley como expresión del contrato social; entre otros.

\footnotetext{
${ }^{1}$ Montesquieu: El Espíritu de las Leyes, México, Editorial Porrúa S.A., 1992, págs. 19 y ss.

${ }^{2}$ Hobbes, Thomas: El Leviatán, Madrid, Editorial Alianza, 2009, págs. 14 y ss.

${ }^{3}$ Beccaria, Cesare: De los Delitos y de las Penas, cuarta edición, Bogotá, Editorial Temis, 1998, págs. 23 y ss.

${ }^{4}$ Rousseau, Juan Jacobo: El Contrato Social, México, Editorial Porrúa S.A., 1989, págs. 33 y ss.
} 
El principio de legalidad fue concebido como manifestación de la igualdad, la libertad y la fraternidad. La libertad reflejada en su esencia, en la materialización de lo intangible de su alcance, de manera que el albedrío del hombre lo conduce a la posibilidad de hacer todo lo que se quiera en tanto no esté prohibido; también la igualdad en la medida que como la ley contiene un mandato universal e impersonal, tiene como destinatarios a la totalidad de los integrantes del pueblo sin distingo alguno; y la fraternidad proyectada en la aspiración de que el mandato legal conduzca a generar la mayor cantidad de felicidad compartida por el más alto número posible de personas.

Así, la legalidad limitó la arbitrariedad del soberano, y modificando la relación del hombre y del poder con la ley, propició la desaparición de los súbditos y el nacimiento de los ciudadanos.

Fue tal la presión ejercida por las ideas libertarias surgidas en la ilustración, que el proyecto revolucionario francés irradió su luz creando un nuevo concepto del hombre y de sus derechos.

$\mathrm{Al}$ amparo del principio de legalidad surgió el derecho penal del Estado liberal, concebido como escenario de protección del reo contra la enorme capacidad de discrecionalidad del soberano, proyectando sus alcances a distintas dimensiones de la convivencia, iniciándose una tradición de respeto por los límites al poder del Estado, que con el paso de los siglos ha sido enriquecida y fortalecida, convirtiéndose en pilar fundamental de la filosofía de los derechos humanos y de las constituciones contemporáneas.

Siendo el principio de legalidad hijo de los principios de libertad, igualdad y fraternidad, tiene además la paternidad responsable del llamado Estado de Derecho. Cuando el artículo $1^{\circ}$ de nuestra Constitución Política declara que Colombia es un Estado Social y Democrático de Derecho, está invocando desde la dimensión del Estado de Derecho, el respeto por el orden jurídico, la tri-división del poder público y el control de las autoridades públicas; todo dentro de la consigna de la exaltación de la dignidad humana. Como se puede observar, el principio de legalidad es patrimonio de la modernidad y conquista medular de los derechos humanos, y a la vez, generador de una tradición jurídica en todo el sistema romano germánico, que por lo mismo debe ser preservado.

2. Sin embargo, el principio de legalidad, tal como fue concebido por el revolucionario francés, suponía la existencia del Estado nacional con presencia de los tres poderes públicos en colaboración armónica y sinceramente comprometidos con el desarrollo del pueblo al que representaban y protegían; siendo las garantías judiciales ante todo talanquera contra el poder arbitrario del soberano; situación que a mediados del siglo XX tendió a modificarse.

Esto porque desde la segunda posguerra del siglo pasado, la comunidad horrorizada por la confrontación bélica, la barbarie y la intolerancia que 
sobrepasaba las fronteras y las capacidades nacionales, comenzó a construir un nuevo derecho penal con dimensión internacional, limitado a cuatro categorías de delitos que ofendían a la humanidad entera: el crimen de agresión, el genocidio, los delitos de lesa humanidad y las infracciones graves contra el derecho internacional humanitario.

Estos llamados "delitos internacionales" generaron una reacción de la comunidad civilizada, en tanto que el titular de los derechos afectados con estas cuatro categorías delictivas era la totalidad de la humanidad, se comenzó a escribir en el contexto internacional un nuevo derecho con unas categorías un tanto distintas a las patrias, precisamente debido al grado de complejidad originado en la inexistencia, tanto de un legislador estricto sensu, como de una autoridad judicial de alcance planetario.

La comunidad universal y la conciencia de la humanidad se convirtieron así en los destinatarios de la protección ofrecida por tal principio de legalidad internacional, de suerte que se modificó, tanto la dimensión a proteger (de lo local a lo global), como la fuente normativa del derecho a aplicar y su redactor.

Se replanteó, en función de la protección de la comunidad orbital, la dogmática del derecho penal internacional, y se redefinió el principio de legalidad.

Es así que el artículo 28 del Estatuto de la Corte Internacional de Justicia ${ }^{5}$ reconoce como fuentes de derecho, con los tratados internacionales, a la costumbre internacional, los principios generales del derecho y la jurisprudencia y la doctrina; superando a la ley como su fuente exclusiva.

Resulta oportuno reconocer que a partir de la vigencia de los Tratados de Derechos Humanos se ha universalizado el compromiso legislativo en pro de su reivindicación y se han precisado los niveles de protección de los habitantes del mundo, en dos sistemas interrelacionados entre sí, con la obligación doméstica de ajustar sus estándares a la sistemática internacional.

Es más, tanto el Pacto Internacional de Derechos Civiles y Políticos como el Pacto de San José y el Convenio Europeo de Derechos Humanos, extienden el principio de legalidad al derecho internacional.

5 "1. La Corte, cuya función es decidir conforme al derecho internacional las controversias que le sean sometidas, deberá aplicar:

a. las convenciones internacionales, sean generales o particulares, que establecen reglas expresamente reconocidas por los Estados litigantes;

${ }^{b}$. la costumbre internacional como prueba de una práctica generalmente aceptada como derecho; c. los principios generales de derecho reconocidos por las naciones civilizadas;

d. las decisiones judiciales y las doctrinas de los publicistas de mayor competencia de las distintas naciones, como medio auxiliar para la determinación de las reglas de derecho, sin perjuicio de lo dispuesto en el Artículo 59.

2. La presente disposición no restringe la facultad de la Corte para decidir un litigio ex aequo et bono, si las partes así lo convinieren". 
Así, el Pacto Internacional de Derechos Civiles y Políticos advierte en su artículo 15 numeral $1^{\circ}$ que "Nadie podrá ser condenado por actos u omisiones que en el momento de cometerse no fueran delictivos según el derecho nacional o internacional."

Pero va más allá en su numeral $2^{\circ}$ en el que de manera tajante advierte: "Nada de lo dispuesto en este artículo se opondrá al juicio ni a la condena de una persona por actos u omisiones que, en el momento de cometerse, fueran delictivos según los principios generales del derecho reconocidos por la comunidad internacional."

Por su parte, el Pacto de San José en su artículo $9^{\circ}$ al consagrar el principio de legalidad no lo limita al derecho patrio señalando que: "Nadie puede ser condenado por acciones $u$ omisiones que en el momento de cometerse no fueran delictivos según el derecho aplicable."

A su turno, el Convenio Europeo de Derechos Humanos al reconocer el principio de legalidad, establece en su artículo $7^{\circ}$ una fórmula similar a la adoptada por el Pacto Internacional de Derechos Civiles y Políticos, al advertir en su numeral $1^{\circ}$ que: "Nadie podrá ser condenado por una acción u omisión que, en el momento en que haya sido cometida, no constituya una infracción según el derecho nacional o internacional." En su numeral $2^{\circ}$, advierte de manera perentoria que: "El presente artículo no impedirá el juicio y el castigo de una persona culpable de una acción o de una omisión que, en el momento de su comisión, constituía delito según los principios generales del derecho reconocidos por las naciones civilizadas."

Esta cláusula colocada, tanto en la Convención Europea como en el Pacto Internacional de Derechos Civiles y Políticos, claramente alude a los principios generales del derecho internacional como fuente de derecho penal internacional, aún frente a la inexistencia de tratado o ley que así lo dispongan.

Tal flexibilización a la legalidad, que implica una restricción a las garantías del justiciable en pro de la lucha contra la criminalidad que agravia a la humanidad, se explica en que con frecuencia se trata de una manifestación delincuencial auspiciada -o sistemáticamente cometida- por los Estados totalitarios, que por supuesto no estarían interesados en legislar tipificando sus propios actos.

La experiencia más temprana de la flexibilización o redefinición del principio de legalidad a escala internacional se vivió en los procesos de Nuremberg ${ }^{6}$, regidos por unos principios, eI primero de los cuales advierte: "Toda persona que cometa un acto que constituya delito de derecho internacional es responsable de él y está sujeta a sanción.". Y en el principio II se estipula que: "El hecho de que el derecho interno no imponga pena alguna por un acto que constituya delito de derecho internacional no exime de responsabilidad en derecho internacional a quien lo haya cometido." Por su parte, en los "Principios

${ }^{6}$ Aprobados por la Comisión de Derecho Internacional de las Naciones Unidas en 1950. 
de cooperación internacional en la identificación, detención, extradición y castigo de los culpables de crímenes de guerra, o de crímenes de lesa humanidad $^{7 \prime}$ se leen los siguientes:

1. Los crímenes de guerra y los crímenes de lesa humanidad, dondequiera y cualquiera que sea la fecha en que se hayan cometido, serán objeto de una investigación, y las personas contra las que existen pruebas de culpabilidad en la comisión de tales crímenes serán buscadas, detenidas, enjuiciadas y, en caso de ser declaradas culpables, castigadas."

2. Todo Estado tiene el derecho de juzgar a sus propios nacionales por crímenes de guerra o crímenes de lesa humanidad."

Así, es claro que sin importar el momento de comisión del delito de guerra el mismo debe ser juzgado, pero a la vez que el Estado en que se cometió tiene derecho a investigarlo y en dado caso a imponer las condenas de rigor.

En el mismo instrumento, en su numeral $8^{\circ}$ se dispone que: "Los Estados no adoptarán disposiciones legislativas ni tomarán medidas de otra índole que puedan menoscabar las obligaciones internacionales que hayan contraído con respecto a la identificación, la detención, la extradición y el castigo de los culpables de crímenes de guerra o crímenes de lesa humanidad."

Así, el principio de legalidad en tratándose exclusivamente de crímenes internacionales -de agresión, de guerra, de lesa humanidad y genocidio, se redefine en función de las fuentes del derecho, ampliándolas en los términos del artículo 38 del Reglamento de la Corte Internacional de Justicia, a los tratados, la costumbre, los principios generales del derecho, la jurisprudencia y la doctrina internacional.

En ese contexto de ampliación del concepto de ley, hay que recordar que nuestro país ha suscrito convenciones internacionales que sancionan delitos internacionales, entre ellos las graves infracciones al derecho internacional humanitario.

Tales Instrumentos fueron incorporados a la legislación interna de nuestro país, ya que mediante la Ley $5^{\text {a }}$ de 1960 se aprobaron los cuatro Convenios de Ginebra de 1949; por la ley 11 de 1992 su Protocolo Adicional I y en virtud de la ley 171 de 1994 el Protocolo Adicional II.

A partir de la vigencia de los artículos 26 y 27 de la Convención de Viena sobre el derecho de los tratados (de 23 de mayo de 1969) se considera que es un principio del derecho de gentes que en las relaciones entre Estados contratantes las disposiciones de derecho interno no pueden prevalecer sobre las de un tratado y que así mismo una parte contratante no puede invocar su propia Constitución ni su legislación interna para sustraerse de

${ }^{7}$ Aprobados por las ONU, en Asamblea General por medio de Resolución 3074 (XXVIII), el 3 de diciembre de 1973. 
las obligaciones que le imponen en derecho internacional el cumplimiento de los tratados vigentes.

Por otra parte, variadas han sido las experiencias en el contexto internacional en las que sin la mediación legislativa local se han aplicado penas originadas en delitos internacionales, construyéndose así la costumbre y jurisprudencia internacional, que han venido aclarando los alcances del principio de legalidad en este contexto; iniciándose con los Juicios de Nuremberg y Tokio, que abrieron el escenario de la llamada justicia internacional, en protección de la humanidad.

También Camboya, país asiático que vivió la tiranía del régimen marxistaleninista-maoista de los Jamer Rojos, con la dictadura de Saloth Sar (llamado Pol Pot), entre el 17 de abril de 1975 y el 6 de enero de 1979, época en la que se exterminó por lo menos a la tercera parte de la población, período en que aquel país se llamó Kampuchea Democrática; crímenes para cuyo juzgamiento se instalaron en el 2006, a instancias de la ONU, Salas Extraordinarias de Juicios, una de las cuales produjo el pasado 26 de julio, la primera sentencia contra Kaing J.C. Eav, alias Duch; en la que se le juzgó y condenó como líder del régimen, no obstante no existir legislación patria que determinara que las atrocidades cometidas contra la población eran consideradas crímenes internacionales.

En Europa, por su parte, el Tribunal Europeo de Derechos Humanos de Estrasburgo en varios pronunciamientos ${ }^{8}$, ha dejado claro que en materia de principio de legalidad, la noción de derecho aplicable se extiende no sólo a las normas escritas de orden nacional sino también al no escrito, haciendo expresa referencia a la jurisprudencia, costumbre y doctrina internacional.

En ese orden, en tratándose de crímenes internacionales la legalidad supone la integración de los tratados internacionales a los sistemas jurídicos domésticos con plenos efectos como ley previa para hacer viable su sanción, así los mismos no estuvieran formalmente tipificados en la legislación nacional al momento de su comisión, tal como se ha concluido en procesos adelantados por las Cortes Supremas de Justicia de Uruguay ${ }^{9}$, Argentina ${ }^{10}$, Chile ${ }^{11}$ y Perú ${ }^{12}$, entre otros.

\footnotetext{
${ }^{8}$ Entre otros, Sentencia de 22 de marzo de 2001, casos "Streletz, Kessler y Krenz contra Alemania" y K.H.W contra Alemania", conocidos como "casos de los disparos mortales en el muro de Berlín".

${ }^{9}$ Caso "Plan Cóndor" en Uruguay, sentencia contra José Niño Gavazzo Pereira y otros; en el mismo sentido la sentencia contra Juan María Bordaberry de 10 de febrero de 2010. ${ }^{10}$ Recurso promovido en representación del Gobierno de Chile (Enrique Lautaro Arancibia Clavel).

${ }^{11}$ Caso Molco de Choshuenco (Paulino Flores Rivas y otros); también Sentencia contra Alberto Fujimori, de 19 de abril de 2009.

12 Recurso de habeas corpus promovido por Gabriel Orlando Vera Navarrete.
} 
Otra fuente de limitación al principio de legalidad en los países del Cono Sur, viene como efecto de la sentencia proferida por la Corte Interamericana de Derechos Humanos el 14 de marzo de 2001 en el caso Barrios Altos (ratificada constantemente), en la que declaró la incompatibilidad de la ley de amnistía y punto final dictada en el Perú, con el Pacto de San José, ley expedida para garantizar la impunidad de crímenes cometidos por organismos o agentes del Estado; se abrió espacio para nuevos juzgamientos de crímenes internacionales en la región.

En ese contexto, la Corte Suprema de Justicia de Argentina, en el conocido como "Caso Simón"13", profirió sentencia el 14 de junio de 2005 dejando sin efecto también unas leyes de punto final y de obediencia debida dictadas en dicho país (las 23.492 y 23.521), que favorecían la impunidad de los delitos cometidos durante los periodos de las dictaduras militares (no obstante que por medio de sentencia de 22 de junio de 1987, ya habían sido declaradas ajustadas a la Constitución del país austral "Caso Camps"); sentencia en la que la Corte convalidó la utilización de una ley ex post facto de orden internacional para imponerles condena, como fue la Convención Interamericana sobre Desaparición Forzada de Personas.

Así, se puede afirmar que so pretexto de la omisión legislativa interna, no es dable abstenerse de castigar los delitos internacionales, en una doctrina construida a partir de casos en que era notoria la incidencia que tenían los perpetradores en los legisladores, quienes ya por intimidación, connivencia o simple indiferencia, se abstenían de incorporar a la legislación nacional la tipificación de tales conductas.

Incluso, desde antes de existir la legislación internacional que sancionaba los crímenes de guerra, era previsible que los mismos fueran a ser tipificados como tales, según sentencia del Tribunal Europeo de Derechos Humanos de 17 de mayo de 2010, en el caso de Vassili Kononov, un exmilitar soviético que fue condenado en el año 2004 por un tribunal de Letonia; sentencia que fue avalada por el Tribunal de Estrasburgo.

Hay que ser enfáticos en señalar que dicha flexibilidad al principio de legalidad es atendible exclusivamente a las cuatro categorías de los llamados delitos internacionales, vale decir a los crímenes de genocidio, agresión, de lesa humanidad y contra el derecho internacional humanitario.

La Sala recientemente se ocupó del asunto reconociendo calidad de fuente de derecho penal a los tratados internacionales suscritos por nuestro Estado

${ }^{13}$ Toda vez que "se imputa a Julio Héctor Simón - por entonces suboficial de la Policía Federal Argentina- haber secuestrado, en la tarde del 27 de noviembre de 1978, a José Liborio Pobrete Rosa en la Plaza Miserere de esta ciudad y, en horas de la noche, a la esposa de éste, Gertrudis Martha Hlaczik, así como también a la hija de ambos, Claudia Victoria Pobrete" quienes después de varios meses de estar en instalaciones militares, desaparecieron sin que se conociera nunca sus paraderos. 
con indiferencia de ley interna que los concrete y viabilice; y por tal razón, desde su entrada en vigencia se legitima la punibilidad de las conductas descritas en tales instrumentos y por tanto se entienden incorporadas al ordenamiento jurídico nacional ${ }^{14}$.

Así, siendo que las conductas contra el llamado Derecho Internacional Humanitario contenidas en los cuatro convenios ginebrinos de 1949 y sus dos protocolos adicionales, tienen rango de Tratado Internacional de Derechos Humanos, son incorporadas automáticamente a la legislación interna desde que se surtieron en nuestro país todos los pasos para que tal calidad pudiera ser predicada de los mencionados acuerdos internacionales.

Desde dicho precedente, aunque referido al delito de genocidio, no importa que la ley que tipifica los crímenes contra el D.I.H. sólo tenga como límite temporal de su inicio el 25 de julio de 2001, ya que desde que los Tratados internacionales fueron suscritos y ratificados por nuestro país, se adquirió la obligación de su positivización y sanción:

\begin{abstract}
"En este orden de ideas -conforme al Bloque de Constitucionalidad establecido mediante los artículos 93 y 94 de la Constitución Política de Colombia, que otorga una prevalencia superior a los Tratados y Convenios Internacionales sobre Derechos Humanos, el ordenamiento jurídico interno de nuestro país debe adecuarse a los principios que, se ha predicado, son de carácter internacional y que orientan las politicas en materia de protección de derechos humanos y sanción por sus violaciones a través de las instituciones estatales establecidas para tal fin-, no puede desconocerse que hace varias décadas existen normas internacionales que han definido cuál debe ser la forma de proceder por parte del Estado Colombiano respecto de lo que se ha referido. En este entendido, no puede ser aceptable que por, la negligencia o dificultad legislativa en promulgar leyes internas que se hubiesen adecuado a dichos derroteros, se pretenda desconocer que a nivel internacional, previo a dicho trámite, ya se había proscrito la comisión del genocidio y se le había categorizado como un crimen atroz desconocedor de la humanidad, así como que su investigación puede hacerse en cualquier tiempo y, en razón de ello, no aplican reglas ni términos de prescripción respecto del ejercicio de la acción penal, civil o administrativa.
\end{abstract}

\begin{abstract}
En síntesis, el Estado Colombiano tiene el deber de cumplir y hacer cumplir, mediante sus Instituciones, de investigar y juzgar las graves violaciones a Derechos Humanos, pues, es su obligación adquirida para con la humanidad mundial, definida mediante los Tratados y Convenios Internacionales que sobre la materia ha suscrito, en atención al principio pacta sunt servanda, así como en los Tratados que no ha suscrito pero que son vinculantes por referirse a Principios de Derecho Internacional, por su pertenencia a la Organización de las Naciones Unidas, por su aceptación de jurisdicción subsidiaria respecto de Organismos Judiciales Internacionales y que en su jurisprudencia le ha recordado y reiterado dichos deberes, como surge del fallo de la Corte Interamericana de Derechos Humanos, fechada el 11 de mayo de 2007, dentro del caso de la Masacre de la Rochela Vs. Colombia..."
\end{abstract}

En síntesis, el Magistrado con Funciones de Control de Garantías de la Sala de Justicia y Paz del Tribunal Superior de Barranquilla no actuó por

${ }^{14}$ Auto de 13 de mayo de 2010, radicado 33118. 
fuera del ordenamiento jurídico al haber revisado la tipicidad de los hechos jurídicamente relevantes formulados en la imputación para efectos de imponer medida de aseguramiento, como lo consideró el Fiscal apelante; pero erró en las consideraciones por medio de las cuales calificó inaplicable la legislación que sanciona los delitos contra el Derecho Internacional Humanitario a las conductas desplegadas por BANQUEZ MARTÍNEZ antes del 25 de julio de 2001, esto es, de la entrada en vigencia de la Ley 599 de $2000(\ldots)^{\prime \prime}$.

\section{COMENTARIO*}

La crisis que hoy vive Colombia -la misma que desde pasadas décadas anega en sangre el suelo nacional- también deja un saldo lamentable en el ámbito jurídico: enfrente al tradicional culto a la Ley que es un valioso legado de los romanos, sobre el cual se intenta erigir el tejido institucional de nuestro Estado de Derecho, los bárbaros contemporáneos han emprendido la tarea de demoler todo el Edificio para, en su lugar, construir un Derecho -si así puede llamársele- que decide caso por caso y se sustenta no en esa tradición legalista sino en el acto político del juez o fiscal de turno, como sucede con el contenido de la providencia objeto de este comentario.

Por eso, el proveído estudiado -después de "reivindicar" el tradicional postulado heredado de los pensadores del iluminismo ${ }^{1}$, a los que por cierto cita con fluidez, y de afirmar que él es "patrimonio de la modernidad y conquista medular de los derechos humanos"-, termina por aseverar que éste, de cara al moderno "Derecho penal internacional", se debe tornar "flexible" cuando se trate de las que denomina "cuatro categorías de delitos internacionales", esto es, genocidio, agresión, lesa humanidad y los que atentan contra el Derecho Internacional Humanitario. Anuncia, pues, "un nuevo derecho penal con dimensión internacional", que deja a un lado la ley como fuente formal y pone su atención a la costumbre, los principios generales del derecho y la doctrina.

Este planteamiento, por supuesto, no es novedoso. Recuérdese, en efecto, que los vientos de un "nuevo derecho" -ahora algunos lo llaman como "neoconstitucionalismo" 2 - fueron los que sacudieron a Europa en la época

\footnotetext{
* Apartes de la ponencia presentada el día 23 de agosto de 2011 con motivo del panel organizado por el Departamento de Derecho Penal, sobre el auto de segunda instancia pronunciado por la Sala de Casación Penal el día 16 de diciembre 2010, radicado 33039, que aquí se inserta.

${ }^{1}$ De forma engañosa, en este aparte de la providencia se empieza por afirmar: "La Sala comienza por reivindicar el principio de legalidad reconocido en nuestra Constitución Política como bastión de protección contra la arbitrariedad". Por supuesto, esta "reivindicación" -que se hace con la pose propia de los juristas defensores de las ideas demoliberalesculmina con una de las más mortales estocadas que la judicatura colombiana, en toda su historia, le haya dado al apotegma en examen y a todo el Derecho penal ilustrado. ${ }^{2}$ Cfr., por ejemplo, GARCía JARAmillo, "El «nuevo derecho» en Colombia", pág. 291.
} 
aciaga de las dictaduras nazi, fascista y franquista, entre otras, que obligaron a juristas de la talla de Piero CalamandReI ${ }^{3}$-concretamente, el 21 de enero de 1940- a pronunciar su famoso discurso "Fe en el Derecho" en el que abogaba por la defensa del derecho de formación legislativa enfrente al de formulación judicial que tiene sus precedentes en la llamada Escuela del Derecho Libre-fundada en Alemania en la primera década del siglo XX-, que tantos beneficios le reportó algunas décadas después a los voceros del derecho penal de autor de la época hitleriana, quienes no dudaron en justificar todos los desafueros del régimen con el argumento de que los jueces quedaban "liberados" de su obligación respecto a la Ley para ceñirse a los principios del gobierno trazados por el Führer ${ }^{4}$.

En Colombia el asunto toma particulares ribetes tras la expedición de la Constitución de 1991 la cual, dicen los partidarios del mencionado enfoque ${ }^{5}$ -aunque algunos pretenden ver la organización social colombiana como un Estado constitucional de Derecho ${ }^{6}$, en contravía de la propia Carta fundamental que habla de un "Estado social de derecho, organizado en forma de República unitaria, descentralizada, con autonomía de sus entidades territoriales, democrática, participativa y pluralista, fundada en el respeto de la dignidad humana", esto es, un modelo de estado social y democrático de derecho ${ }^{7}-$, posibilita un viraje en estas materias que, por supuesto, mucho daño ha hecho en el ámbito del Derecho penal que de la mano de una corriente expansionista -a ratos con el pretexto de defender el llamado derecho penal de enemigo- pisotea todo el legado de occidente concretado en el programa penal de la Constitución y que los Códigos penales intitulan como "Normas Rectoras de la Ley Penal Colombiana" o "principios rectores".

Por eso, en el pasado más reciente, tanto la Sala de Casación Penal ${ }^{8}$ como la Corte Constitucional ${ }^{9}$-y, por supuesto, la Fiscalía General de la Naciónproclaman el imperio de institutos tan odiosos como la imprescriptibilidad de la acción penal, la aplicación retroactiva de la misma en desfavor del reo -cosa que también se hace en el caso en examen-, la analogía in malam partem, la constitucionalidad de los tipos penales indeterminados, la conformidad con la Carta fundamental de penas privativas de la libertad de muy larga duración, la aplicación directa de los tratados internacionales sin

\footnotetext{
${ }^{3}$ Véase, Fe en el Derecho, págs. 79 y 80.

${ }^{4}$ Un buen resumen de la doctrina de la época en MüLLER Los juristas del horror, págs. 101 y ss.

${ }^{5}$ Cfr., por ejemplo, García Jaramillo, "El «nuevo derecho» en Colombia”, pág. 292.

${ }^{6}$ Véase ZAGReBelsky, El derecho dúctil, págs. 21 y ss.

${ }^{7}$ Para la caracterización de los diversos modelos, en especial éste último que es el colombiano, Véase Díaz, Estado de Derecho, págs. 1 y ss.

${ }^{8}$ Véase, por ejemplo, Auto del día trece de mayo de 2010, radicado 33118 que, por lo demás, se apoya en diversos pronunciamientos sobre la materia.

${ }^{9}$ Bien significativas, entre muchas otras decisiones, son las sents. C-578 de 30 de julio 2002 y C-580 de 31 de julio 2002.
} 
que pasen por el tamiz del Congreso de la República ni sean desarrollados por las leyes. Es más, se introducen en forma directa, como en los tiempos más aciagos del positivismo ferriano, consideraciones de tipo peligrosista propias de un derecho penal de autor en contravía de uno de acto, no sólo en el ámbito del derecho penal sustantivo sino en el procesal; se desconocen elementales principios en materia de la valoración de los medios de prueba; se pisotea el debido proceso, etc. En fin, se arrasa de manera franca y abierta con el ideario demoliberal que inspira el programa penal de la Constitución vertido en los títulos preliminares de los Códigos Penal y de Procedimiento Penal y, en su lugar, con el pretexto de aplicar el "nuevo derecho", el Derecho penal es ahora lo que digan los jueces de turno.

Por ello, para los redactores de la providencia en examen suena desafinado que un Magistrado con Funciones de Control de Garantías de la Sala Penal del Tribunal Superior de Barranquilla, con ocasión de la aplicación del procedimiento de la mal llamada Ley de Justicia y Paz, reivindique -de verdad-el principio de legalidad de los delitos y de las penas y se niegue a imputarle a un temible criminal paramilitar los crímenes cometidos antes del 25 de julio de 2001 como atentados contra el Derecho Internacional Humanitario y, en su lugar, se los atribuya como comunes.

Es más, de manera harto preocupante, en ese proveído se afirma que "... en tratándose de crímenes internacionales la legalidad supone la integración de los tratados internacionales a los sistemas jurídicos domésticos con plenos efectos como ley previa para hacer viable su sanción, así los mismos no estuvieran formalmente tipificados en la legislación nacional al momento de su comisión, tal como se ha concluido en procesos adelantados por las Cortes Supremas de Justicia de Uruguay, Argentina, Chile y Perú, entre otros"10; y se añade que ella reconoce "calidad de fuente de derecho penal a los tratados internacionales suscritos por nuestro Estado con indiferencia de ley interna que los concrete y viabilice; y por tal razón, desde su entrada en vigencia se legitima la punibilidad de las conductas descritas en tales instrumentos y por tanto se entienden incorporadas al ordenamiento jurídico nacional".

Es decir, se pretende que es lícito y viable pisotear el orden jurídico para dar primacía a los tratados internacionales que, ahora, pueden ser aplicados de forma automática en Colombia como si la Constitución no señalara los mecanismos para incorporarlos al ordenamiento patrio (art. 150 num. 16) -que no acoge las concepciones monistas radicales en materia de las relaciones entre el derecho internacional y el nacional, en virtud de las cuales la norma internacional ni siquiera requiere ser incorporada al ordenamiento interno $^{11}$ - y no existiese un modelo de Estado definido en la Carta Política

\footnotetext{
${ }^{10}$ Así, también, en el Auto de trece de mayo de 2010, radicado 33118, contra el Dr. César Pérez García.

${ }^{11}$ Cfr. Valencia Restrepo, Derecho Internacional Público, pág. 143.
} 
que impide semejante exabrupto ${ }^{12}$. Es más, tras esa postura se evidencia una ignorancia crasa en materia de los dictados del derecho internacional público que, como advierte el Profesor Hernán Valencia Restrepo en su monumental tratado sobre la materia, conoce diversos sistemas en materia de las relaciones entre el derecho internacional y el derecho interno yendo desde las concepciones dualistas o pluralistas, pasando por las monistas, hasta llegar a las denominadas tesis coordinadoras que encuentran acomodo en el ordenamiento patrio ${ }^{13}$.

Incluso, tan atrevida, arbitraria e injurídica afirmación -que reniega del carácter preexistente de la ley penal en relación con el hecho imputado como, sin distinción alguna lo pregona el art. 29 inciso $2^{\circ}$ constitucional: "Nadie podrá ser juzgado sino conforme a leyes preexistentes al acto que se le imputa, ante juez o tribunal competente y con observancia de la plenitud de las formas propias de cada juicio"- desconoce de manera franca y abierta lo dispuesto por la propia Constitución en su artículo 93 inciso $1^{\circ}$ cuando afirma que "Los tratados y convenios internacionales ratificados por el Congreso, que reconocen los derechos humanos y que prohíben su limitación en los estados de excepción, prevalecen en el orden interno" con lo cual, en esta materia -recuérdese: en materia de derechos humanos-, se le da carácter supraconstitucional al derecho internacional convencional que no puede ser pisoteado -jaún por el Juez más encumbrado!-, así se parta de la premisa de que se trata de perseguir crímenes internacionales.

¡Cómo cambian los tiempos! La que hasta hace unos pocos años era una decisión ajustada a Derecho, ahora se ha convertido en una contraria al mismo; lo que en este momento entiende la Sala de Casación Penal como loable, hasta hace pocos años era tildado como una conducta constitutiva de un posible prevaricato... Ese es, pues, el "nuevo Derecho" que se pregona con bombos y platillos y que -en medio de una mediocridad académica pasmosa- invade todos los escenarios de la Administración de Justicia en Colombia, con un lamentable saldo para la seguridad jurídica que va camino del despeñadero, pues ya nadie conoce el Derecho aplicable ni sabe cuáles son las fronteras entre lo lícito y lo ilícito. ¡Estamos, pues, en manos de los jueces...!

${ }^{12}$ La providencia en comento, incluso, no duda en reconocer que el apotegma de legalidad es el bastión del Estado de Derecho: "Siendo el principio de legalidad hijo de los principios de libertad, igualdad y fraternidad, tiene además la paternidad responsable del llamado Estado de Derecho".

${ }^{13}$ Cfr. Derecho Internacional Público, págs. 137 y ss. La Constitución, recuérdese, también dispone en el art. $9^{\circ}$ inciso $1^{\circ}$ que "Las relaciones exteriores del Estado se fundamentan en la soberanía nacional y en el reconocimiento de los principios del derecho internacional aceptados por Colombia", por lo cual se adopta un sistema automático selectivo en materia de la recepción por los derechos internos del derecho internacional principial y consuetudinario (ídem, pág. 147). 
De todo lo expresado y de cara a un necesario debate en torno a tan delicado asunto, puede colegirse lo siguiente: En primer lugar, ciertamente el panorama actual de la Administración de Justicia en Colombia, en general, y de la penal en particular, no podía ser más lamentable: los esfuerzos por construir un derecho penal liberal que tantos derramamientos de sangre le han costado al género humano se ven, de momento, truncados; por doquier ronda el temor, el escepticismo, la desconfianza. Cualquiera puede hoy se prendido, perseguido y conducido ante los jueces de turno que son los que personifican el derecho.

En segundo lugar, debe decirse que así como sucedió en aquellos momentos en los cuales en la primera mitad del siglo XVI CASTELLIO luchaba contra Calvino, muy bien descritos por la pluma de Stefan Zweig, en Colombia no estamos lejos de tener que decir: "Cuando en un Estado cada ciudadano ha de contar en todo momento con que puede ser interrogado, examinado o juzgado, cuando sabe que sobre cada una de sus acciones y de sus palabras acecha constantemente una invisible mirada escrutadora, cuando, tanto de día como de noche, la puerta de su casa puede abrirse inesperadamente para un brusco registro, entonces los nervios se ablandan progresivamente y se produce el miedo en masa, al que por contagio sucumben los más valientes"14.

Sin embargo, en tercer lugar, enfrente a las corrientes autoritarias que pretenden llenar todos los espacios, este es el momento para reivindicar el ideario demoliberal y retomar la prédica de los grandes pensadores que con sus elaboraciones han hecho posible el estado moderno para izar enhiestas las banderas de la legalidad. Llegó, pues, la hora de predicar con PIERO CALAMANDREI -como en la Italia atormentada de 1940- la fe en el Derecho y de gritar con él a los cuatro vientos que "cuando se trata del Derecho, el barco es de todos. Porque en este barco del Derecho están embarcados la dignidad y las esperanzas, el honor y la vida de cada uno de nosotros"15.

Por supuesto, en cuarto lugar, quienes hoy de forma insolente y altanera despedazan el principio de legalidad $\mathrm{y}$, con él todo el orden jurídico constituido -después 2500 años de evolución del Derecho ${ }^{16}$, deben tener muy claro que algún día tendrán que responder no sólo ante el tribunal de la historia por la debacle causada sino ante las cortes de los hombres por sus actos y, como suele suceder, un día serán vencidos por el peso de la ley y su nefasto proyecto autoritario será derrotado.

\footnotetext{
${ }^{14}$ Véase ZWEIG, Castellio contra Calvino, pág. 75.

${ }^{15}$ Cfr. Calamandrei, Fe en el Derecho, pág. 104.

${ }^{16}$ Sobre esa evolución, Véase Welzel, Introducción a la Filosofía del Derecho, pág. 5.
} 


\section{BiBLIOGRAFÍA}

Pueden consultarse los siguientes textos:

Beccaria, Cesare: De los delitos y de las penas, trad. y estudio preliminar de Francisco Tomás y Valiente, Madrid, Aguilar, 1979.

Bettiol, Giuseppe: Istituzioni di diritto e procedura penale, $3^{\mathrm{a}}$ ed., Padova, Cedam, 1980.

Calamandrei, Piero: Fe en el Derecho, traducción y prólogo de Perfecto Andrés Ibáñez, Madrid, Marcial Pons, 2009.

Cicerón, Marco Tulio: Tratado de la República. Tratado de las Leyes. Catilinarias, trad. De Francsico Navarro y Calvo/Juan Bautista Calvo, México, $4^{\circ}$. Ed., Porrúa, 1981.

CRISTIANI, ANTONIO: Istituzioni di diritto e procedura penale, Milano, Dott. A. Giuffrè, 1983.

De Secondat, Charles de (Barón de la Bréde y de Montesquieu): Del espíritu de las leyes, trad. de Nicolás Estévanez, Buenos Aires, Editorial Claridad, 1971.

DíAz, Elías: Estado de Derecho y sociedad democrática, Madrid, Taurus, 1983.

García Jaramillo, Leonardo: "El «nuevo derecho» en Colombia: ¿Entelequia innecesaria o novedad pertinente?", en Revista de Derecho, Universidad del Norte-Barranquilla, $\mathrm{N}^{\circ} 29$, Bogotá, 2008, págs. 289-330.

Mantovani, Ferrando: Principi di Diritto penale, Padova, Cedam, 2002.

Feuerbach, Paul Johann Anselm von: Tratado de derecho penal, trad. de Eugenio Raúl Zaffaroni e Irma Hagemeier de la $14^{a}$. Ed., Buenos Aires, Hammurabi, 1989.

Hall, Jerome: "El principio de legalidad", trad. de Roberto Vernengo en La ley, núm. 54, Buenos Aires, La Ley, 1959, págs. 809 y ss.

JiMÉNEZ DE AsúA, Luis: Tratado de derecho penal, t. II, $4^{\text {a }}$ ed., Buenos Aires, Losada, 1977.

KreY, Volker: Keine Strafe ohne Gesetz, Berlin/New York, Walter de Gruyter, 1983.

Muñoz Conde, Francisco: Introducción al derecho penal, Barcelona, Bosch, 1975.

MülLER, INGo: Los juristas del horror, traducción de Carlos Armando Figueredo, Bogotá, Libreraría Jurídica Álvaro Nora, 2009.

Platon: Las Leyes. Epinomis. El Político, Estudio introductivo y preámbulo a los diálogos por Francisco Larroyo, México, $3^{a}$. ed., Porrúa, 1979.

Rodríguez Mourullo, Gonzalo: "Legalidad (principio de) derecho penal", en Nueva Enciclopedia Jurídica, t. XIV, Barcelona, Seix, 1971, págs. 882 y ss. 